rectal tube should be left for a few days for continuous drainage of urine, and after this time frequent evacuation should be encouraged. The fluid intake must be high, and $4 \mathrm{~g}$. of sodium bicarbonate taken daily. If thirst or lethargy are experienced, a salt-free diet is prescribed and $8 \mathrm{~g}$. of bicarbonate given. If dehydration is progressive and nausea and vomiting occur, the patient must be admitted to hospital for full biochemical investigation. Marked acidosis or hypokalaemia will require careful intravenous replacement therapy. In hypocalcaemia, in addition to correction of acidosis, vitamin $\mathrm{D}_{2}$ should be given by mouth in adequate dosage to restore a positive calcium balance, that is, 10,000 to 100,000 units a day (Harrison, 1958).

\section{Cutaneous Ureterostomy}

Bilateral cutaneous ureterostomy has had few advocates because storage of the urine depends upon an external appliance worn over each stoma. It has not proved easy to carry out the operation without sloughing of the ureter or stricture formation. Those most adept in its performance have advised against any indwelling drain, and some advocate a spout fashioned as a skin pedicle for neat collection of the ureteric efflux. The expectation that the method might avoid deleterious effects upon the kidney does not seem to be realized, and its advantage in cases of renal deterioration from ureteric obstruction is equally offered by an isolated intestinal segment.

\section{BIBLIOGRAPHY}

BAIRD, J. S., SCOTT, R. L., and SPENCER, R. D. (1917), Surg. Gynec. Obstet., 24, 482.

BOLlman, J. L., and MANN, F. C. (1927), Proc. Soc. exp. Biol. Med., 24, 923.

BOYCE, W. H. (1951), F. Urol., 65, 241.

BOYD, J. D. (1931), Amer. F. Dis. Child., 42, 366.
BRICKER, E. M. (1950), Surg. Clin. N. Amer., 30, 1511 . COFFEY, R. C. (rg1 I), F. Amer. med. Ass., 56, 397.

CORDONNIER, J. J. (i949), Surg. Gynec. Obstet.; 88, 44 I. CORDONNIER, J. J., and SPJUT, H. J. (1957), \%. Urol., 78, 242. CORTES, S. T. (1946), Bol. Trab. Acad. Argent: Cir., 30, 558. DANIEL, O., and SHACKMAN, R. (1952), Brit. F. Urol., 24, 334. DEPAGE, A., and MAYER, L. (1904), Arch. klin. Chir., 74, 71. FERRIS, O. D., and ODEL, H. M. (1950), F. Amer. med. Ass., 142, 634 .

GEER, W. A., and DRAGSTEDT, L. R. (1938), Anin. Surg., 108, 263.

GERSUNY, R. (1898), Wien. klin. Wschr., Ix, 990, quoted by Foges.

GOODWIN, W. E., HARRIS, A. P., KAUFMAN, J. J., and BEAL, J. M. (1953), Surg. Gynec. Obstet., 97, 295.

HARRISON, A. R. (1958), Brit. F. Urol., 30, 455.

HARTMAN, F. W. (1933), f. exp. Med., 58, 649.

HARVARD, B. M., and THOMPSON, G. J. (1951), f. Urol., 65,223 .

HINMAN, F. A., and WEYRAUCH, H. (1936), Trans. Amer. Ass. gen.-urin. Surg., 29, 15.

HOPEWELL, J. P. (1959), Ann. Roy. Coll. Surg. of Eng., 24159. JACOBS, A., and STIRLING, W. B. (r952), Brit. ₹. Urol., 24, 259. JOHNSON, T. H. (1956), Ұ. Urol., 76, 380.

KINMAN, L. M. SAUER, D., HOUSTON, W. T., and MELICK, W. F. (1953), A.M.A. Arch. Surg., 66, 531. LAPIDES, J. (I95I), Surg. Gynec. Obstet., 93, 691.

LEADBETTER, W. F. (I95I), F. Urol., 65, 818.

LOWSLEY, O. S., and JOHNSON, T. H. (1955), f. Urol., 73, 83. MARTIN, F. H. (1900), Amer. Gynec. Obstet. F., 16, 395.

MAUCLAIRE, P. (1895), Ann. Mal. Org. gen.-urin., 13, 1080. MERSHEIMER, W KOLARSICK, $A$., and KAMMANDEL, (1950), Bull. N.Y. med. Coll., 13, 71.

NASH, D. F. ELLISON (1956), Brit. f. Urol., 28, 387.

NESBIT, R. M. (1949), f. Urol., 6r, 728.

PARSONS, F. M., PYRAH, L. N., POWELL, F. J. N.,, REEI G. W., and SPEIRS, F. W. (1952), Brit. F. Urol., 24, 317.

POWELL, K. A. (1949), Brit. F. Surg., 36, 421 .

PYRAH, L. N. (1957), f. Urol., 78, 683.

RICKHAM, P. P. (1956), Brit. F. Urol., 28, 394.

SIMON, J. (1852), Lancet, ii, 568.

SMITH, G. I., and HINMAN, F. Jnr. (1955), f. Urol., 74, 354

STAMEY, T. A. (1956), Surg. Gynec. Obstet., 103, 736.

STEVENS, A. R. (194I), f. Urol., 46, 57.

STILES, H. (1911), Surg. Gynec. Obstet., 13, 127.

TICHOFF, P. I. (1908), Zbl. Chir., 35, rog.

TIZZONI, G., and FOGGI, A. (1888), Zbl. Chir., 15, 921.

VERHOOGEN, J. (1908), Assoc. franc. Urol., 12, 352.

VERMOOTEN, V. (1934), f. Urol., 32, 273.

WELLS, C. A. (1956), Brit. F. Urol., 28, 335.

WITZEL, O. (1891), Zbl. Chir., 18, 601.

Bibliography continued from page 648-Kenneth Owen, M.S., F.R.C.S.

\section{BIBLIOGRAPHY}

DE CAMP, P. T., and BIRCHALL, R: (1958), Surgery, 43, 134.

FREEMAN, N. E., LEEDS, F. H., ELLIOTT, W. G., and ROLAND, S. I.' (1954), F. Amer. med. Ass., 156, 1077.

GELLMAN, D. D. (1958), Quart. F. Med., 27, 105.

GOLDBLATT, H., LYNCH, J., HANZEL, R. F., and SUMMERVILLE, W. W. (1934), Э. exp. Med., 59, 347.

HOWARD, J. E, CONNOR, T. B., and THOMAS, W. C. (1956),

Trans. Ass. Amer. Phys., 69, 291.
PEART, W. S. (1959), personal communication.

POUTASSE, E. F. (1956), Circulation (N.Y.), 13, 37.

POUTASSE, E. F., and DUSTAN, H. (1956), Cleveland Clin. CU

Quart., 23, 3.
POUTASSE, E. F., HUMPHRIES, A. W., McCORMACK, L. J., 穴 and CORCORAN, A. C. (1956), $\mathscr{y}$. Amer. med. Ass., 161, 419.6

ROB, C. G., EASTCOTT, H. H. E., and OWEN, K. (1956), $\frac{\bar{D}}{\mathscr{D}}$ Brit. $\mathcal{F}$. Surg., 43, 181 .

THOMPSON, J. E., and SMITHWICK, P. J. (1952), Angiolagy? 3, 493. 


\title{
RENAL ARTERY STENOSIS
}

\author{
By KenNeth Owen, M.S., F.R.C.S. \\ Consultant Surgeon to St. Mary's Hospital and to St. Peter's Hospital
}

Since the discovery by Goldblatt, Lynch, Hanzel and Summerville (r934) that hypertension in the dog can be caused by partial occlusion of the renal artery there has been an endless search by physicians and surgeons for surgically curable renal lesions in patients with hypertension. Patients with clinical hypertension have been cured by nephrectomy in such diseases as pyelonephritis, hydronephrosis, and renal tuberculosis, but there is no clear relationship between these conditions and the Goldblatt lesion and results have, on the whole, been unpredictable and disappointing.

Recently, however, it has been recognized that partial occlusion of a renal artery may be responsible for hypertension in man, either as a single lesion or as a complication of the Leriche syndrome of aortic thrombosis (Thompson and Smithwick, 1952; Poutasse, 1956; Freeman, Leeds, Elliott and Roland, 1954; Fig. I). The most common cause of such lesions is atheroma, but a number of cases of congenital stenotic lesions have been reported in children. There are numbers of isolated examples of many other types of pathology, such as thromboangeitis, emboli, tumour and hydatid cysts.

The majority of the atheromatous lesions occur at the extreme proximal end of the renal artery although occasional lesions have been reported more distally (De Camp and Birchall, 1958). The presumably humoral hypertension produced by these lesions progresses rapidly to produce the characteristic changes of malignant hypertension, and the raised pressure produces necrotizing arteriolitis in the opposite kidney. The kidney on the affected side is protected from the raised pressure by the arterial obstruction and may, therefore, be potentially the better kidney. This is of obvious importance when considering treatment and is a reason for favouring reconstruction of the artery as opposed to nephrectomy, despite the greater magnitude of the former operation. When greater experience has been gained of the results of arterial surgery in this situation it may even be that an indication might arise for reconstructive surgery on the affected side followed by nephrectomy on the contralateral side should extensive arteriolar changes have occurred.

\section{Diagnosis and Selection of Cases}

The definitive diagnosis of these cases depends upon aortography but it would seem unjustifiable to subject all hypertensive patients to this major investigation. It is, therefore, of importance to find clinical criteria for selecting patients for aortography. Hypertension due to renal arterial lesions does not usually have the family history which frequently occurs with malignant hypertension, which is commonest in the fourth and fifth decades, and it is rapidly progressive. There may be a slight diminution in the kidney size on intravenous pyelography. Evidence of vascular insufficiency in the lower limbs and inability to maintain an erection may suggest aortic thrombosis.

Gellman (1958), in summarizing the views of Poutasse and Dustan (1956), gives the following indications for aortography:-

I. Patients with unexplained disparity in renal size or function on intravenous pyelography.

2. Young patients with no family history of hypertension and no other primary cause.

3. Elderly patients with rapidly progressive hypertension.

4. Patients with rapidly progressive hypertension, particularly when associated with pain in the flank.

These indications are only relative in the light of present rather small experience and it is probable that they will need modification as further experience is gained. As atheroma is so common in patients of the malignant-hypertension age-group it might be expected that atheromatous plaques in the renal artery would be common and the indication for aortography may become widened in this group. Selective renal function tests following bilateral ureteric catheterization may be of value, with the measurement of plasma clearances, water and electrolyte excretion. Howard, Connor and Thomas (1956) found that 


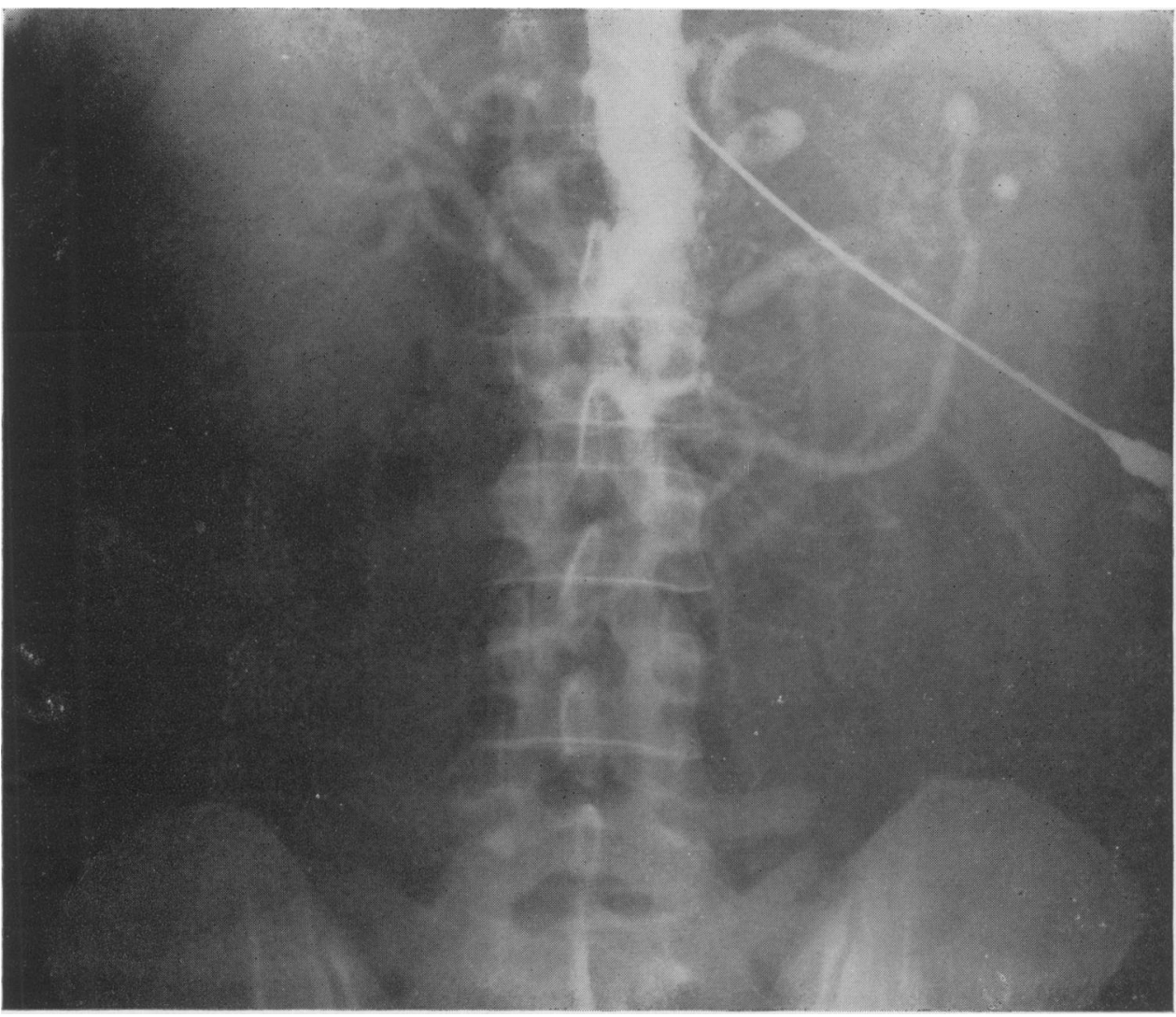

FIG. I.-Aortogram of a patient, aged thirty-nine, with hypertension (B.P. 205/1 10 mm.) and severe buttock claudication, showing stenosis of left renal artery and thrombosis of the aorta. The right renal artery was also found to be stenosed at operation. Thrombendarterectomy of the upper aorta and right renal artery was performed with left nephrectomy and an aortic bifurcation graft. He is now symptom-free and normotensive three years after operation.

there was a lower sodium concentration and usually a diminished water output on the affected side. In a series at present being investigated at St. Mary's Hospital these findings have been confirmed (Peart, 1959), although De Camp and Birchall (1958) state that the urinary sodium and potassium determinations have been capricious.

\section{Aortography}

This investigation is essential to the diagnosis and may be performed percutaneously or by femoral catheterization. The lesion is seen as a localized stenosis of the renal artery usually close to the aorta (Fig. I). The subsequent nephrogram may give evidence of a diminution in the size of the kidney.

\section{Treatment}

The simplest form of surgical treatment is nephrectomy on the affected side, but this has the disadvantage that the better kidney may be sacrificed (as has been discussed earlier) and it offers no solution in the bilateral case.

Reconstructive surgery is, therefore, considered 3 the treatment of choice in those patients who are considered fit for such major procedures, nephrectomy being reserved for failed reconstructive cases $ᄋ$ and for patients only judged fit enough for the less major procedure. Gellman (1958) has recently윽 described a case in which nephrectomy was per- $\rightarrow$ formed by Sir Eric Riches with relief of hypertension, the patient's general condition contra- $\bar{N}$ indicating surgical treatment of his aortic throm- $\sigma$ bosis. There is also a review of other cases treated $N$ by nephrectomy and thrombendartectomy in this paper.

A number of general principles apply whichever 0 reconstructive operation is used. The approach is $\overparen{D}$ anterior through a long paramedian incision or a $\stackrel{\oplus}{\rightarrow}$ transverse incision, the left renal artery being ap- 


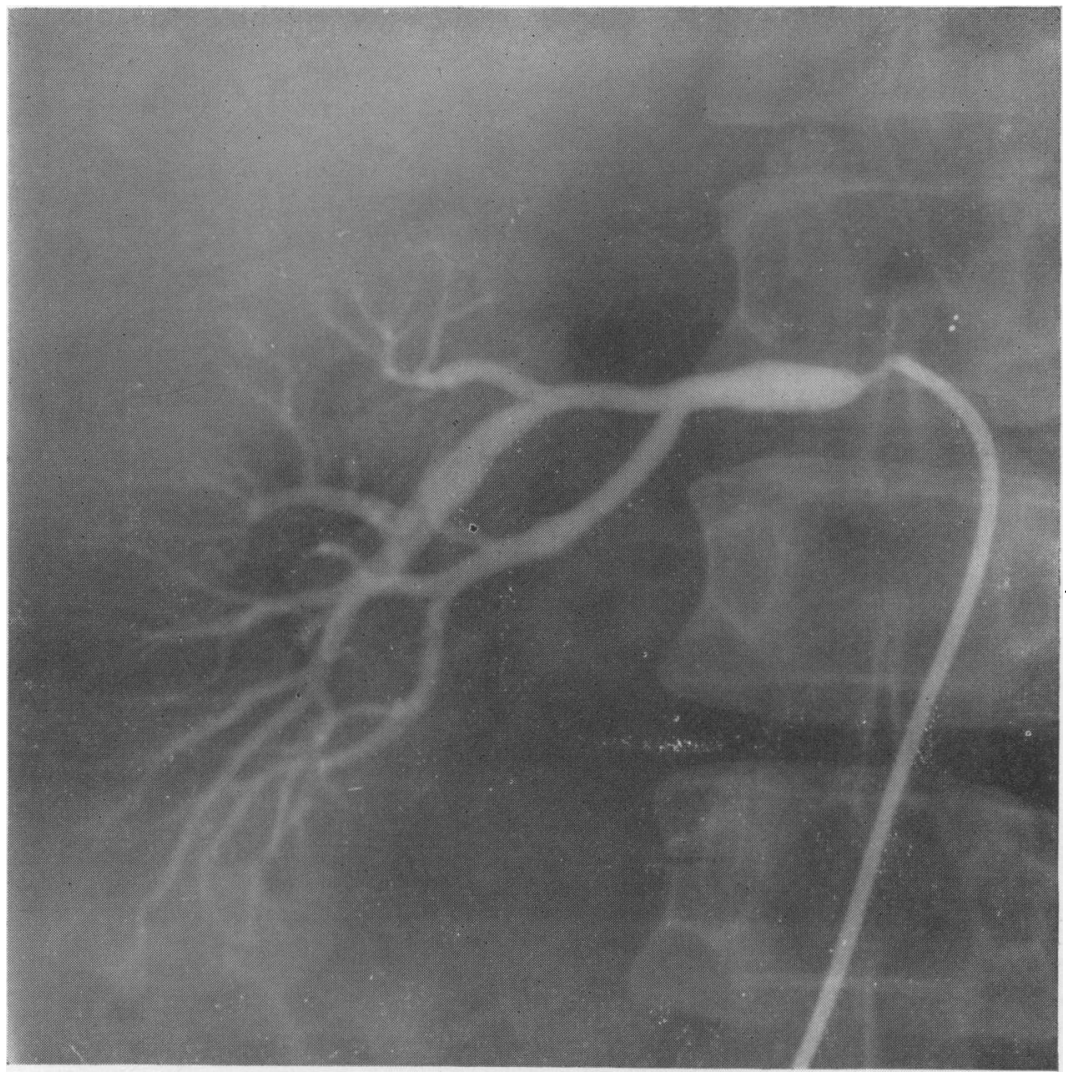

FIG. 2.-Right renal arteriogram of a patient, aged forty-eight, who presented with visual changes and had a severe hypertension (B.P. 290/1 $50 \mathrm{~mm}$.). There was a diminution in the size and excretory power of the right kidney on intravenous pyelography, and the renal arteriogram shows a stenosis of the right renal artery. This vessel was disobliterated from within the aorta with a marked post-operative drop in the blood pressure (B.P. 170/100 mm.).

proached by dissecting between the spleen and splenic flexure and retracting the spleen and pancreas upwards and to the right. The right renal artery is displayed by reflecting the duodenum and pancreas to the left.

The pressures in aorta and renal artery are measured, the demonstration of a pressure drop across the stenosis being the final step in the diagnosis. If a pressure drop is not found, the hypertension is unlikely to be due to the arterial lesion. It seems wise to take biopsy specimens from both kidneys in order to assess prognosis and the advisability of any further treatment such as nephrectomy should the reconstructive operation fail. Hypothermia is not necessary in most cases, although its use may be considered should a long grafting operation be considered. The upper aortic clamp is applied obliquely so that the blood flow to the opposite kidney is not affected.
The following surgical procedures have been suggested and successes have been recorded with most of them:-

I. Thrombendarectomy.

2. Excision of stenosed segment and end-to-end anastomosis or re-anastomosis to aorta.

3. Excision and insertion of a graft.

4. Anastomosis of splenic or colic artery, endto-side, to the renal artery distal to the stenosis.

5. By-pass arterial homograft from aorta to distal renal artery.

\section{Thrombendarectomy}

This is the operation of choice in cases of Leriche syndrome (Rob, Eastcott and Owen, 1956) and has given some of the earlier successes in concomitant renal artery obstruction (Freeman 
et al., 1954), the renal artery origin being disobliterated from within the aorta.

In the juxta-aortic lesion it seems important to open the aorta and remove a circle of atheromatous intima (about $\frac{1}{2}$ in. diameter) from the aortic wall, besides removing the plaque in the renal artery. In one casc treated by the author an apparently localized plaque close to the aorta was removed through an incision in the renal artery with the establishment of a good pulsatile flow. There was a good initial drop in the systemic blood pressure post-operatively, but this rose again after a few days and it was demonstrated aortographically that the vessel had thrombosed.

A similar plaque in a subsequent case (Fig. 2) was removed through an incision in the aorta and a fringe of aortic intima could be demonstrated projecting across the origin of the renal vessel. Removal of a circle of intima produced a smooth in-flow and a good result.

Thrombendartectomy has the advantage that it is a fairly quick procedure and it does not involve the risks of multiple suture lines or of graft failure. The risks of infection are also probably less than those of a grafting operation.

\section{Excision and Re-anastomosis}

This would appear to be a suitable operation for a lesion in the middle of the renal artery as in a case reported by De Camp and Birchall, but its use in the juxta-aortic lesions should be approached with caution. The familiar diagram of the renal artery emerging from the aorta at a right angle suggests that it should be easy to re-insert the artery after dividing it distal to a stenosis. On closer examination of the origin of these vessels, however, it is found that they run downwards for a short distance on emerging from the aorta before turning laterally, and this acute angle is probably of importance in securing a full flow from the aorta. Slight variations in the angulation and site of the new anastomosis may produce significant differences in the renal blood flow, and the presence of atheroma in the aortic wall may be a further difficulty in making a satisfactory anastomosis.

\section{Excision and Insertion of a Graft}

It is possible that long obstruction may occasionally call for this treatment but the results from end-to-end grafting in femoral arteries has been found disappointing compared with by-pass grafting and it is probable that the same principles apply in this situation.

Poutasse, Humphries, McCormack and Corcoran (1956) have suggested inserting an aortic graft into the aorta and anastomosing its renal branch to the divided renal artery for the juxta-aortic lesions, but this seems an unnecessarily extensive pro- cedure compared with disobliteration or by-pass grafting.

\section{Anastomosis of Splenic Artery to Renal}

End-to-side anastomosis of the splenic to the renal artery has been practised with success but, 0 although this is an ingenious solution to the problem, it is only applicable on the left side and there are theoretical objections to employing a long tortuous artery which may itself be atheromatous.

\section{By-pass Graft}

A by-pass graft from the aorta to the distal renal artery would seem a suitable procedure should the length of stenosis be unduly great.

\section{Post-operative Treatment}

The immediate post-operative treatment is $\overrightarrow{0}$ similar to that for any major abdominal operation, intravenous fluids and gastric suction being used for several days as prophylactic treatment of paralytic ileus.

In common with other vascular operations it probable that the chances of early post-operative thrombosis are governed by mechanical factor $\$ \frac{\Phi}{3}$ It is thought that anticoagulants are unlikely make a significant difference to the early resulgo and their use involves considerable risk of wound $\vec{\varphi}$ haematomata and haemorrhage. Long-term ant coagulant treatment may, however, be considere毒 of value in preventing progression of the original vascular disease.

Indwelling ureteric catheters may be of value for a few days after operation, the measurement of water and sodium excretion being a guide to the maintenance of the re-established renal blood flow.

\section{Summary}

It is now established that a number of cases of malignant hypertension are due to lesions of the $\exists$ renal artery, and surgical treatment of these lesions may produce reversal of the hypertensive changes. From present reports it would appear that this is 8 a relatively uncommon cause of hypertension, but $₹$ the possibility of cure in this otherwise fatal con- 을 dition would appear to justify a more intensive search for such cases which may be commoner than present figures would indicate.

\section{Acknowledgments}

I am grateful to Professor W. S. Peart for $\stackrel{N}{\omega}$ referring the case illustrated in Fig. 2, to Professor 0 Charles Rob for permission to quote the case 0 illustrated in Fig. I, and to Dr. David Sutton for $\overparen{D}$ the aortograms of these cases.

Bibliography continued on page 644 . 